\title{
Editorial
}

\section{Osteoporosis and prostate cancer}

\author{
T Dhillon' and J Waxman*,I \\ 'Department of Cancer Medicine, Faculty of Medicine, Imperial College of Science, Technology \& Medicine, Hammersmith Campus, Du Cane Road,
} London WI2 ONN, UK

British Journal of Cancer (2003) 89, 779-780. doi: 10.1038/sj.bjc.660II9I www.bjcancer.com

(c) 2003 Cancer Research UK

Prostate cancer has just become the most commonly registered cancer of males in the United Kingdom, overtaking lung cancer in the registration sweepstakes, and is the second most common cause of male cancer deaths. Deaths have trebled over the last 30 years, plateauing in the mid-1990s but recently increasing again (Office for National Statistics, 2001).

Locally advanced and metastatic prostate cancer is treated with antiandrogens and the importance of the side effects of treatment have become more significant as the incidence of this malignancy has increased. These side effects from treatment range from hot flushes, impotence, breast tenderness and enlargement, and diarrhoea to the physically more significant side effects, which include anaemia, loss of muscle bulk, neurological dysfunction, and osteoporosis. All of these side effects occur as a consequence of androgen deficiency. We would argue that the development of osteoporosis is the most important of these side effects and that we need to be more proactive in our management of this condition.

The risk of osteoporotic fracture as a consequence of antiandrogen therapy has been described in five studies. In a group of 235 patients with prostate cancer, the cumulative risk of fracture at 7 years was $28 \%$ in 59 castrated men and $1 \%$ in 176 men treated with a GnRH agonist (Daniell, 1997). In a second study, 9\% of 224 men treated with an LHRH agonist had a fracture over a median follow-up of 22 months; seven of these men had fractures resulting from osteoporosis, eight men from trauma, and five of mixed aetiology (Townsend et al, 1997). In a third study of 218 men, $6 \%$ had an osteoporotic fracture during 6 or more months treatment with anti-androgen therapy (Hatano et al, 2000); in a fourth study, $20 \%$ of 181 men treated for 10 years had osteoporotic fractures (Oefelein et al, 2001). Fracture rates were described in 429 men with prostate cancer treated by bilateral orchiectomy. There were 267 fractures in 161 men. The increased risk due to osteoporosis was reported as a standard incidence ratio of 3.50 (95\% CI 2.71-4.43) (Melton et al, 2003).

The increased risk of fracture in these men is due to accelerated loss of bone mineral density and is of early onset. Decreases of $6.6 \%$ at the lumbar spine have been seen only after 6 months of treatment and decreases of $6 \%$ at the femoral neck after 18 months treatment (Diamond et al, 1998). In a French study, changes in bone mineral density were evaluated in 12 men with prostate cancer treated with triptorelin. Men with metastases, radiographic

\footnotetext{
*Correspondence: Professor JWaxman; E-mail: j.waxman@imperial.ac.uk
}

evidence of osteoporosis, or pre-existing conditions associated with accelerated bone loss were excluded from the study. Bone mineral density was measured at baseline, 6,12 , and 18 months. Bone mineral density of the lumbar spine and femoral neck tended to decrease from month 6 , but only reached statistical significance at 18 months (Maillefert et al, 1999). In an American study, changes in bone mineral density were evaluated in 26 men with prostate cancer treated by orchiectomy or with GnRH agonists. Bone mineral density was measured at 6-42 months. The average bone mineral density of the hip decreased by $7.6 \%$ during the first orchiectomy, and similar rates of bone loss were observed among men treated with the GnRH agonists. Rates of bone loss were highest among inactive and obese men (Daniell et al, 2000).

These significant changes in bone mineralisation can be prevented. This has been shown by a recent study, where patients with locally advanced or recurrent nonmetastatic prostate cancer receiving leuprolide were randomised to receive pamidronate given every 3 months for 1 year. In the bisphosphonate group bone mineral density did not decrease, while in the control group mineralisation decreased by $3.3 \%$ in the lumbar spine and $2.1 \%$ at the hip (Smith et al, 2001). This benefit has been confirmed in an Australian study (Diamond et al, 2001) and in an American study where 106 patients were randomised to receive 3 monthly Zoledronic acid for 1 year (Smith et al, 2003a). An alternative approach might be to use an antiandrogen without adverse effects on bone. Bicalutamide monotherapy increases serum levels of testosterone and oestradiol, indicating that osteoporosis might be less likely than with other antiandrogens. Urinary markers of bone turnover in bicalutamide-treated patients were higher than in gonadotrophin-releasing hormones against treated patients (Smith et al, 2003b). However, there have been no studies that have assessed bone mineralisation densities in patients treated with bicalutamide as compared with other antiandrogens. In clinical practice, bicalutamide is frequently given with a gonadotrophinreleasing hormone agonist and the effects of this combination on bone turnover are not known.

So, it would appear that there is a clear way to limit the effects of antiandrogen treatment on bone and that is by giving bisphosphonate treatment prophylactically. What is unclear is the bisphosphonate dosage regimen to be used. There are new, highly effective third-generation bisphosphonates curr-ently available and it may be that a limited trial is required to investigate this issue of dosage and frequency of bisphosphonate administration. 


\section{REFERENCES}

Daniell HW (1997) Osteoporosis after orchiectomy for prostate cancer. J Urol 157: 439-444

Daniell HW, Dunn SR, Ferguson DW, Lomas G, Niazi Z, Stratte PT (2000) Progressive osteoporosis during androgen deprivation therapy for prostate cancer. J Urol 163: $181-186$

Diamond T, Campbell J, Bryant C, Lynch W (1998) The effect of combined androgen blockade on bone turnover and bone mineral densities in men treated for prostate carcinoma: longitudinal evaluation and response to intermittent cycle etidronate therapy. Cancer 83: $561-566$

Diamond TH, Winters J, Smith A, De Souza P, Kersley JH, Lynch WJ, Bryant C (2001) The antiosteoporosis efficacy of intravenous pamidronate in men with prostate carcinoma receiving combined androgen blockade: a double blind, randomized, placebo-controlled crossover study. Cancer 92: 1444-1450

Hatano T, Oishi Y, Furuta A, Iwamuro S, Tashiro K (2000) Incidence of bone fractures in patients receiving LH-releasing hormone agonists for prostate cancer. Br J Uro Int 86: $449-452$

Maillefert JF, Sibilia J, Michel F, Saussine C, Javier RM, Tavernier C (1999) Bone mineral density in men treated with synthetic gonadotropin-releasing hormone agonists for prostate carcinoma. J Urol 161: $1219-1222$
Melton III LJ, Alothman KI, Khosla S, Achenbach SJ, Oberg AL, Zincke H (2003) Fracture risk following bilateral orchiectomy. J Urol 169 (5): $1747-1750$

Oefelein MG, Ricchuiti V, Conrad W, Seftel A, Bodner D, Goldman H, Resnick M (2001) Skeletal fracture associated with androgen suppression induced osteoporosis: the clinical incidence and risk factors for patients with prostate cancer. J Urol 166: $1724-1728$

Office for National Statistics (2001), Website address: www.statistics gov.uk/statbase/explorer.asp

Smith MR, Eastham J, Gleason DM, Shasha D, Tchekmedyian S, Zinner N (2003a) Randomized controlled trial of zoledronic acid to prevent bone loss in men receiving androgen deprivation therapy for nonmetastatic prostate cancer. J Urol 169 (6): 2008-2012

Smith MR, Fallon MA, Goode MJ (2003b) Cross-sectional study of bone turnover during bicalutamide monotherapy for prostate cancer. Urology 61 (1): $127-131$

Smith MR, McGovern FJ, Zietman AL, Fallon MA, Hayden DL, Schoenfeld DA, Kantoff PW, Finkelstein JS (2001) Pamidronate to prevent bone loss during androgen-deprivation therapy for prostate cancer. $N$ Eng J Med 345 (13): $948-954$

Townsend MF, Sanders WH, Northway RO, Graham Jr SD (1997) Bone fractures associated with LH-releasing hormone agonists used in the treatment of prostate carcinoma. Cancer 79: 545-550 